\title{
Analizando el valor social de Altamira
}

David Barreiro, Felipe Criado-Boado | Instituto de Ciencias del Patrimonio (Incipit), Consejo Superior de Investigaciones Científicas (CSIC)

URL de la contribución <www.iaph.es/revistaph/index.php/revistaph/article/view/3559>

\section{RESUMEN}

Se presenta una primera síntesis y valoración de los resultados obtenidos en el proyecto Valor Social de Altamira, llevado a cabo en el marco del Programa de Investigación para la Conservación Preventiva y Régimen de Acceso de la Cueva de Altamira entre septiembre de 2012 y agosto de 2014.

El proyecto pretendía profundizar en la caracterización de Altamira como enclave patrimonial mediante una estrategia multidisciplinar e interdisciplinar. El análisis parte de una modelización del proceso de producción de valor patrimonial en torno a Altamira, lo que permite distinguir las distintas dimensiones valorativas implicadas (existencial, de legado, documental, estética, política, económica, pedagógica), atendiendo tanto a los valores objetivados (en cosas y personas) como a los subjetivados (los discursos).

A lo largo del artículo se exponen los resultados obtenidos; se integran, en tanto provenientes de fuentes diversas; y se contrastan con las hipótesis y valoraciones previas manejadas en relación con las diferentes dimensiones valorativas que componen el modelo. Llegando a la conclusión de la conveniencia de abordar cualquier plan de gestión de enclaves patrimoniales, especialmente de aquellos muy delicados o con graves amenazas de deterioro, mediante estrategias inclusivas y participativas.

\section{Palabras clave}

Conservación preventiva | Cueva de Altamira | Habitantes | Investigación | Población | Territorio | Valores patrimoniales | Visitantes | 


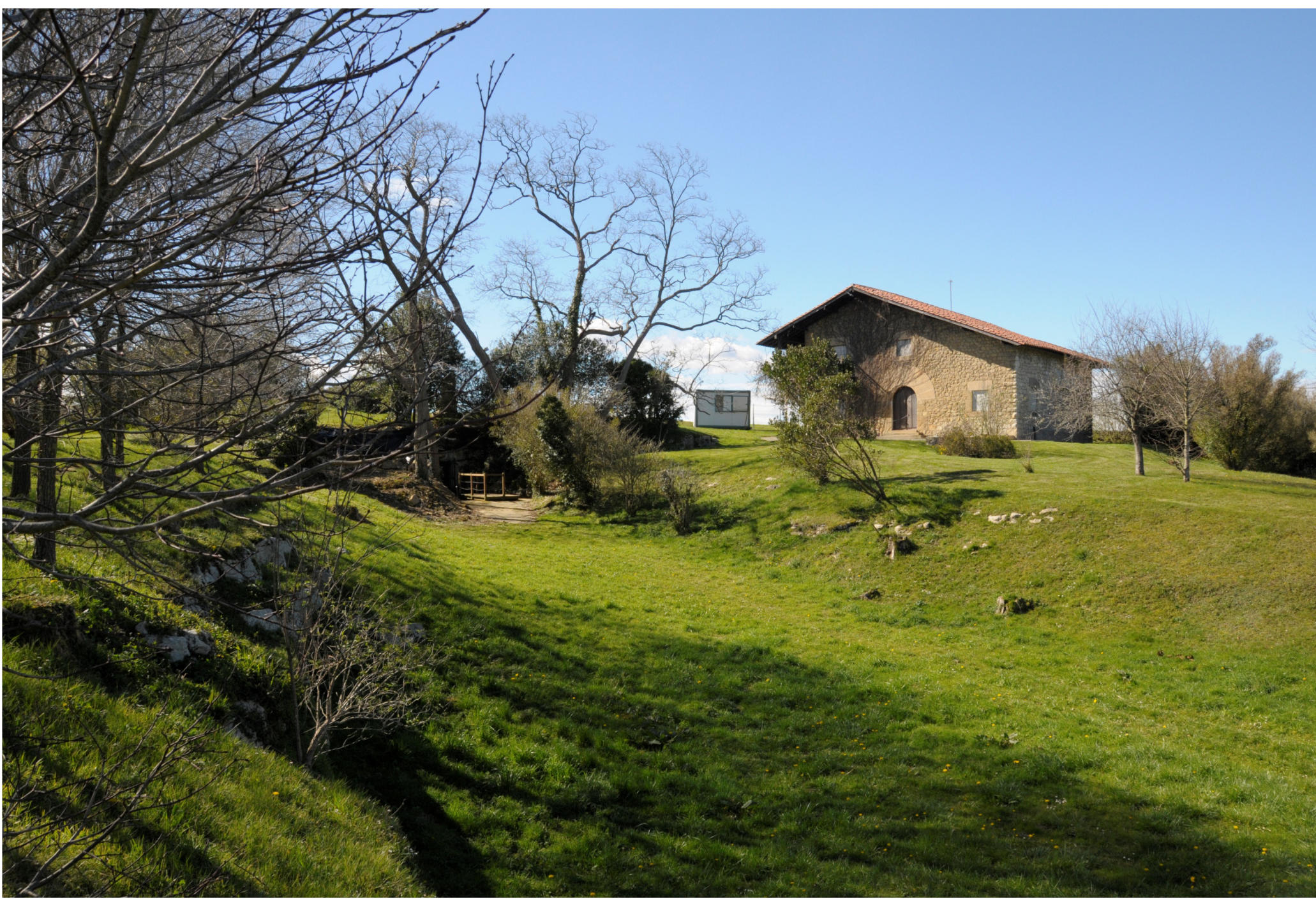

Aspecto actual de la entrada a la Cueva de Altamira (Cantabria, España) | foto Felipe Criado-Boado 


\section{PRESENTACIÓN}

En agosto de 2012, el Patronato del Museo de Altamira aprobó el Programa de Investigación para la Conservación Preventiva y Régimen de Acceso de la Cueva de Altamira (en adelante Programa Altamira), cuya dirección científica estuvo a cargo de Gaël de Guichen (ICCROM), y su coordinación a cargo de Marián del Egido y Concha Cirujano, del Instituto del Patrimonio Cultural de España, con la colaboración de la Subdirección General de Museos Estatales. La duración para esta investigación era de dos años desde septiembre de 2012, habiendo finalizado el 31 de agosto de 2014. Como parte de este Programa se desarrolló el Proyecto Valor Social de Altamira (en adelante Proyecto VSA). Se presenta aquí una primera síntesis y valoración de los resultados obtenidos en el mismo.

\section{OBJETIVOS DEL PROYECTO VSA}

La finalidad principal del proyecto era profundizar en la caracterización de Altamira como enclave patrimonial. Esto concierne a la entidad y sus circunstancias desde el redescubrimiento hasta la actualidad: asumimos que Altamira es historia contemporánea. Nos propusimos analizar Altamira como entidad compleja, polisémica y multidimensional, a la que sólo podíamos acceder a través de una estrategia multidisciplinar e interdisciplinar, intentando obtener datos, hasta donde fuese posible, integrados y comparables (ya que no, en muchos casos, conmensurables).

Los resultados del análisis deberían servir, como los de los restantes proyectos del Programa Altamira, para optimizar las condiciones de gestión del sitio. El Plan de Conservación Preventiva contempla algunas acciones derivadas de los resultados obtenidos por nosotros, pero su eficacia sólo podrá ser evaluada pasado un tiempo razonable, por lo que en el presente texto no nos detendremos en este aspecto y nos limitaremos a exponer los resultados de la investigación.

El Proyecto VSA se fijó una serie de objetivos de carácter general:

1. Identificar las diferentes dimensiones del valor de uso de Altamira.

2. Estudiar el impacto social de Altamira en clave cuantitativa y contemporánea.

3. Dimensionar el impacto económico directo o inducido en el entorno y prever el impacto económico de la apertura de la cueva y sus hipotéticos efectos. 4. Estudiar la percepción social de Altamira en clave simbólica, incluyendo la percepción y visibilización del debate sobre su posible apertura.

5. Estudiar el impacto y uso social de Altamira en diferentes prácticas discursivas: la ciencia, el arte, la educación y la comunicación, introduciendo una perspectiva histórica y diacrónica. 
6. Contribuir a la propuesta global del Plan de Conservación Preventiva de la cueva.

El objetivo 1 constituyó, por sí mismo, la generación del marco teórico en el que imbricar el proceso y sus resultados. Los objetivos 2 a 5 se trataron de cubrir mediante una estrategia multidisciplinar que explicamos más abajo. El objetivo 6, como hemos dicho, no lo desarrollaremos aquí.

\section{LA TEORÍA: IDENTIFICANDO VALORES DE USO}

Partimos de una noción específica: todo patrimonio es producido mediante un proceso dialéctico de objetivación y subjetivación de valor (BARREIRO, 2012: 37-39). El primer objetivo de la investigación fue la identificación de las dimensiones valorativas implicadas en este proceso, en el que intervienen las personas y las cosas. Desde nuestro punto de vista, el enfoque dialéctico evita, por un lado, la equiparación de la capacidad de agencia de las cosas con la de las personas, y la fetichización de aquéllas, que es uno de los problemas de la visión subjetivista (como las teorías de Latour); por otro lado, evita la minusvaloración de los efectos sociales de las cosas (un problema del neopositivismo y la tecnocracia), y su reducción a meros artículos de consumo (el patrimonio como espectáculo).

Este proceso se articularía mediante una serie de fases lógicas como refleja el concepto de "cadena de valor", definido por Criado (1996) y González (1999), que ha sido necesario actualizar (imagen 1):

1. la apropiación, en la que entra en juego la cosmovisión del sujeto que valora, por la que una entidad primaria adquiere la condición de patrimonial (GONZÁEZ-PÉREZ; PARCERO-OUBIÑA, 2011);

2. una sucesión de valorizaciones sobre dicha entidad (lo social objetivado y subjetivado), en la que intervienen la producción de conocimiento, la esfera práctico-moral y la práctico-expresiva; y

3. una meta-valorización, que se traduce en la capacidad de producir valor a través del patrimonio como un recurso para el desarrollo (en la acepción global de este término).

Los valores de Altamira se encontrarían, desde esta concepción, objetivados en una multitud de objetos y productos, y subjetivados en una multiplicidad de actores y productores. Mediante una combinación de enfoques objetivistas (centrados en lo que los objetos nos dicen, incluyendo las personas en sus comportamientos y actitudes) y subjetivistas (lo que las personas expresamente nos cuentan o nos contaron, a través de la palabra, el sonido o la imagen) y de técnicas cuantitativas y cualitativas, pretendimos obtener una visión global de lo que es y ha sido Altamira. 


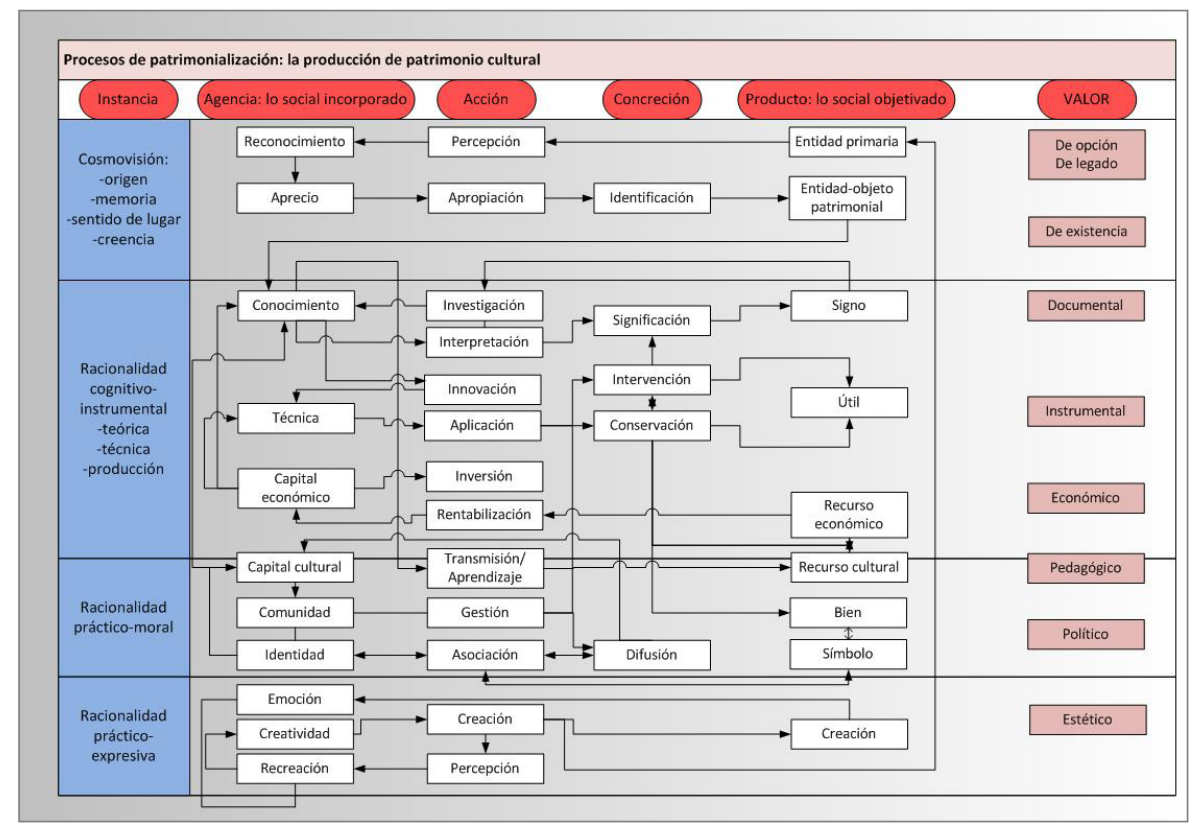

1. Modelo de producción de patrimonio cultural | imagen David Barreiro

\section{DISCIPLINAS IMPLICADAS Y ESTUDIOS REALIZADOS}

Especialistas de ámbitos diversos colaboraron en el diseño, ejecución y análisis de los diferentes estudios, cada uno de los cuales fue conducido conforme a los criterios y procedimientos de varias disciplinas, con la siguiente estructura:

$>$ Estudio sociológico.

$>$ Estudio económico.

$>$ Estudio antropológico.

$>$ Estudio del libro de visitas.

$>$ Estudio Altamira en los medios y en la red.

$>$ Estudio Altamira en el arte.

$>$ Estudio Altamira en la cultura material.

$>$ Estudio Altamira en la ciencia.

$>$ Estudio Altamira en la escuela.

En el caso de los tres primeros, el papel principal de cada una de las disciplinas implicadas hizo que el mismo estudio se caracterizase desde ese punto de vista (sociológico, económico, antropológico). Estos fueron los estudios nucleares del Proyecto VSA, dado que su objeto de estudio eran los propios agentes sociales que valoran Altamira.

Como primer paso en el diseño de la metodología se efectuó una aproximación cualitativa al objeto de estudio. La recopilación inicial de informa- 


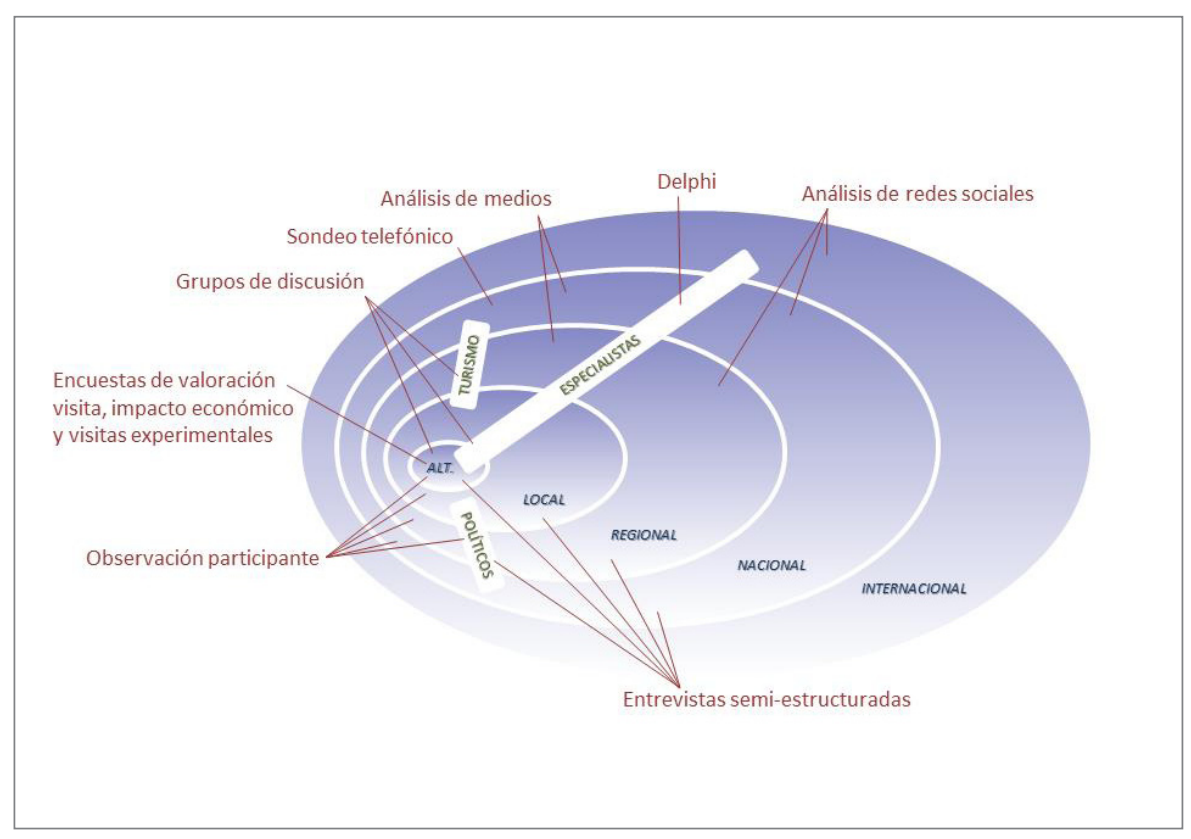

2. Técnicas de estudio aplicadas a cada escala de público | imagen Virtudes Téllez Delgado

ción implicó diferentes niveles y unidades de análisis (búsqueda de fuentes secundarias, realización de entrevistas semiestructuradas, diseño de un panel de expertos) en el arranque del proyecto (inicios de 2013).

A partir de ese momento fue posible diseñar una aproximación cuantitativa (desde la sociología y la economía), a través de la técnica de la encuesta. Al mismo tiempo, se profundizó en la aproximación cualitativa inicial. Para ello se delimitaron los ámbitos territoriales y lugares concretos en los que Altamira se dota de significado social, para, a continuación, determinar los actores e instituciones que participan en la gestión y toma de decisiones. También se identificaron otros agentes o actores sociales que no participan directamente en dicha gestión, pero que se sienten concernidos por ella.

Todo esto permitió abarcar, desde técnicas sociológicas y antropológicas diversas, una variedad significativa de actores a diferentes escalas (imagen 2) y elaborar un guion de trabajo articulado con base en tres ámbitos territoriales (local, autonómico y central; imágenes 3 a 5).

Los restantes estudios discurrieron en paralelo al grueso del trabajo sociológico y antropológico, y sus resultados fueron el producto de la acción e interacción de disciplinas diversas: ciencias de la comunicación (análisis de discursos y de contenidos), semiótica (análisis iconográfico), arqueología, historia, historia del arte, cienciometría, con la colaboración, igualmente, de las disciplinas principales del Proyecto VSA (sociología, economía, antropología). 


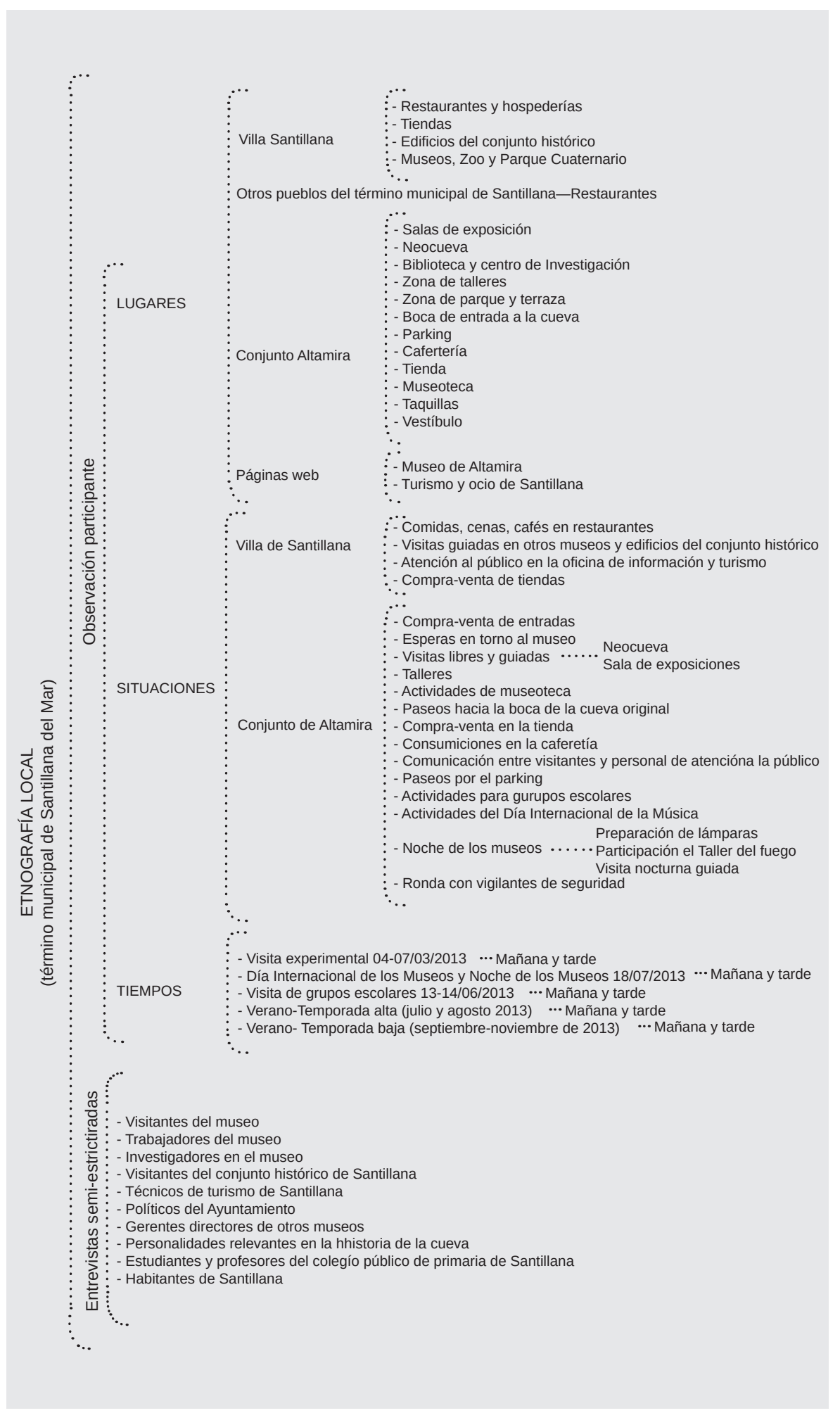

3. Esquema de guión de trabajo. Escala 3 | esquema Virtudes Téllez Delgado 


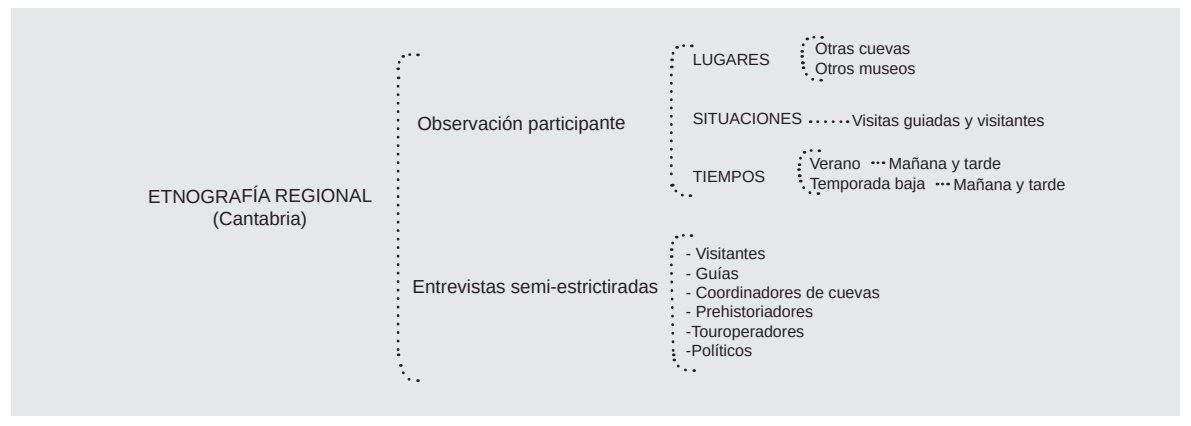

4. Esquema de guión de trabajo. Escala 2

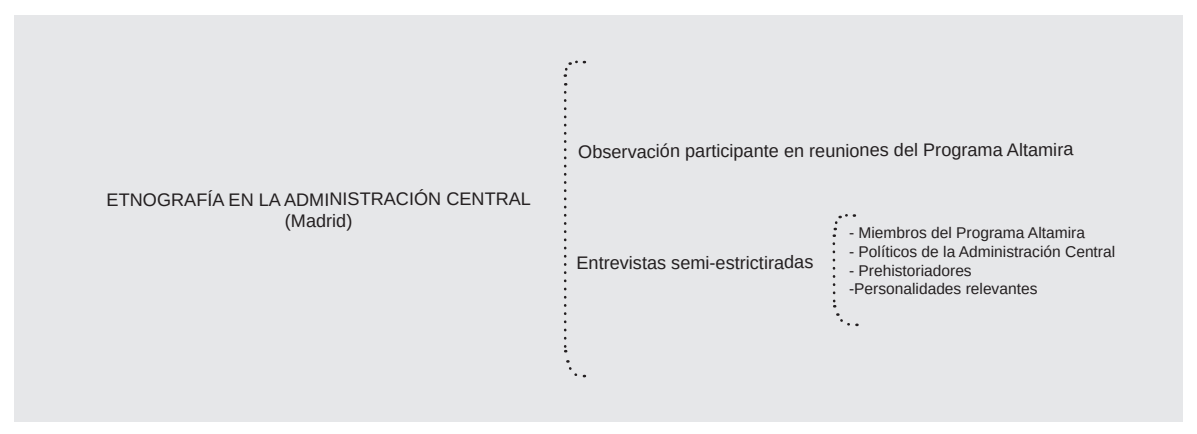

5. Esquema de guión de trabajo. Escala 1 | esquemas Virtudes Téllez Delgado

\section{RESULTADOS}

\section{Trabajo realizado}

Los estudios sociológico y económico fueron realizados a partir de la ejecución de un sondeo sobre dos poblaciones distintas: los visitantes al museo y la población a escala estatal. Se diseñaron cuestionarios dirigidos a propiciar, por un lado, un doble estudio del público del Museo de Altamira (uno orientado a la valoración de la visita en términos de satisfacción con la misma, y otro orientado a la obtención de los datos necesarios para el estudio de impacto económico) y, por otro, un estudio de la opinión pública en general (trabajando separadamente con las escalas autonómica y estatal, e incorporando preguntas de interés para los diferentes estudios). El trabajo de campo del sondeo a los visitantes del museo fue realizado entre los meses de agosto de 2013 y febrero de 2014, en tres oleadas (para obtener datos significativos respecto a la estacionalidad), cubriendo un total de 1.028 cuestionarios. El sondeo telefónico se llevó a cabo en abril de 2014, abarcando una muestra aproximada de 1.000 cuestionarios.

En el marco del estudio antropológico se realizó un trabajo de campo de seis meses (entre junio y noviembre de 2013), basado en la observación participante, complementado con técnicas de producción y observación de discursos particulares (se realizaron 145 entrevistas semi-estructuradas indi- 
viduales o colectivas, y grupos de discusión). Además, se trabajó con fuentes documentales proporcionadas sobre todo por los trabajadores del Museo de Altamira y del sector turístico de Santillana.

El Proyecto VSA lo completaron una serie de estudios más específicos, que se fueron desarrollando simultáneamente a los anteriores, focalizados en diferentes segmentos:

1. "Altamira en los medios y en la red" consistió, por un lado, en un análisis de las distintas informaciones publicadas sobre Altamira entre los años 2001 a 2004, 2009 y 2013, en diversos medios de comunicación. Por otro lado, se realizaron sondeos en diferentes redes sociales, entre febrero y mayo/junio de 2014.

2. Se llevó a cabo un análisis del contenido del libro de visitas de Altamira, un género específico de discurso que nos permitió identificar patrones de regularidad en las quejas y sugerencias de los visitantes.

3. "Altamira en el arte" se realizó con base en una documentación sistemática de referencias gráficas, textuales y orales a la influencia estética del sitio a lo largo de su historia. Estas referencias han ido siendo recopiladas a lo largo de varios años de trabajo por parte del personal del Museo de Altamira.

4. "Altamira en la cultura material" es un análisis del uso de la imagen de Altamira como reclamo comercial, símbolo identitario, emblema o decoración en objetos diversos de uso cotidiano. Estos objetos (53), mayoritariamente, forman parte de los fondos documentales del Museo de Altamira.

5. "Altamira en la ciencia" es un estudio cienciométrico en el que se trabajó con dos tipos de indicios de relevancia: el número de citas recibidas y la presencia en repertorios bibliográficos, catálogos y repositorios, a través del uso de bases de datos e índices de citación.

6. "Altamira en la escuela" es un análisis enfocado en los textos e imágenes de los manuales escolares. En concreto, se basó en un vaciado selectivo, buscando una muestra cronológicamente amplia (entre 1900 y 2007) de los fondos bibliográficos del proyecto de investigación MANES (Manuales Escolares Españoles), ubicado en la Biblioteca Central de la UNED.

Todos estos estudios fueron realizados por diferentes especialistas (hasta un total de 17) y un buen número de colaboradores de diverso tipo de acuerdo con las líneas estratégicas definidas por el equipo de dirección.

Con vistas a una puesta en común de los resultados obtenidos, previa a la elaboración de los informes finales, se realizó un taller, de dos días de duración, a principios de junio de 2014, que juntó a todas las personas responsables de los distintos estudios. En esta actividad fue posible establecer un fructífero diálogo que permitió minimizar los efectos de un trabajo parcelado en diferentes estudios disciplinares para consolidar una valoración y unas conclusiones comunes. 


\section{Síntesis de resultados}

Nuestra hipótesis previa se basaba en una intuición acerca de la aparente pérdida de relevancia social de Altamira en los últimos cuarenta años, que podría estar relacionada con la fragilidad de las pinturas, sus problemas de conservación, y la consiguiente indefinición en el régimen de acceso a la cueva durante estos años. Esta hipótesis ha sido comprobada mediante los distintos estudios, y considerando las diferentes dimensiones del valor (valor de legado, existencial, estético, documental, político, económico, pedagógico).

La principal conclusión a la que hemos llegado es que se habría producido, por un lado, una pérdida de ciertos aspectos relacionados con el disfrute, debido a sus problemas de conservación, y, por otro, un proceso de normalización, ya que Altamira ha perdido peso como elemento simbólico-identitario en el conjunto de la población española (lo que significa que se ha aliviado el peso de esa carga sobre sus otros valores), aunque no en la relación entre Cantabria y Estado español, y, además, ha perdido peso específico (que no excepcionalidad) en el conjunto de un patrimonio mundial que no hace sino incrementarse día a día (incluido el arte rupestre).

En lo que respecta a la dimensión existencial (o qué presencia tiene Altamira en el imaginario colectivo e individual), algunos datos obtenidos a escala estatal revelan un conocimiento relativamente amplio de Altamira entre la población (82,9\%), pese a que un $69,4 \%$ de la población nunca la ha visitado (un $40,9 \%$ de ellos incluso desconoce la existencia del museo).

El conocimiento entre la población extranjera residente en España, como dato adicional significativo, es mucho menor que el de la población oriunda. Además, respecto a la situación actual de la cueva, un 67,3\% de la población sabe que no es accesible a las visitas, mientras el resto $(32,7 \%)$ no lo sabe; pero lo significativo es que, para la población entre 18 y 39 años, este último índice asciende al 50. Esto podría estar indicando una pérdida de relevancia entre los más jóvenes. Incluso entre la población local hemos detectado un desplazamiento generacional en el concepto "Altamira", asociándolo a la cueva original la gente de entre 40 y 50 años, y asociándolo los más jóvenes al conjunto actual (en el que el Museo juega un papel central respecto a la cueva original).

Otro síntoma de esta pérdida entre los jóvenes es el carácter institucional de la mayoría de las noticias aparecidas en los medios de comunicación (la fuente casi siempre es el Museo, o el Ministerio de Cultura, o el gobierno de Cantabria), lo que indica una escasa presencia de Altamira motivada por agentes no institucionales. Esta tendencia se confirma en la red Twitter, donde el número de tweets valorativos o comentarios de opinión es notable- 
mente reducido (un 5\%). El ámbito preponderante es, además, la cornisa cantábrica, siendo Madrid la única zona alejada con presencia significativa. Los vínculos identitarios se restringen al ámbito regional.

En relación con esto también destaca la desvinculación emocional de los jóvenes de la zona respecto a la cueva: no tienen recuerdos de su/s visita/s, ni nostalgia por ello. Además, no encuentran en el discurso museográfico los lazos identitarios tramados con antelación por sus mayores respecto a la cueva.

En conclusión, salvo en el caso de los medios de comunicación estudiados, para los que sigue siendo una referencia temática, Altamira ha perdido relevancia, a nivel subjetivo (que es lo que evalúa la dimensión existencial) en medios y agentes, locales y estatales, lo cual es achacable tanto a la restricción del acceso (para el imaginario de la población local, más que para sus condiciones objetivas, como veremos) como a la normalización del valor del sitio, en relación directa con el incremento constante y progresivo de nuevos lugares y enclaves patrimoniales; Altamira pierde relevancia en el imaginario colectivo porque cada vez hay más sitios (reales o imaginarios) relevantes para esa heterogénea colectividad.

La dimensión del valor de legado hace referencia a la estima que suscita un determinado bien en tanto elemento que merece ser preservado para su disfrute por las generaciones futuras. Es decir, forma parte esencial de la condición patrimonial y plantea una tensión inherente a ésta: la que se da entre las posibilidades de uso y las exigencias de conservación. En el caso de Altamira, ésta tensión es un elemento crucial.

Salvo en los libros de texto y manuales escolares, donde la temática de la conservación y sus problemas sigue ausente incluso en los más recientes, el resto de los análisis revelan que el valor de legado ha ido adquiriendo cada vez mayor presencia en los diferentes medios, así como en la opinión de los agentes. Las figuras de reconocimiento patrimonial (Altamira fue declarada patrimonio mundial en 1985) han consolidado esta dimensión. El porcentaje de visitantes que sabe que la cueva está cerrada al público $(84,1 \%)$ crece respecto a la población que lo sabe a escala estatal $(67,3 \%)$, y aumenta significativamente el porcentaje de gente que ve bastante bien o muy bien que la cueva esté cerrada para garantizar su conservación futura (95,5\%), dado que es de toda la humanidad (para el 59\%). Además, el índice de satisfacción con la visita al museo es significativamente alto: la visita a la neocueva es puntuada con un 5,91 sobre 7 , y el conjunto del museo con un 5,88 sobre 7 .

En los libros de visitas se constata que numerosos ciudadanos comprenden las cautelas tomadas para preservar la cueva de cara al futuro, pero muchos 
visitantes ya no se conforman con su papel de sujetos pasivos, y quieren formar parte de los procesos de generación de conocimiento sobre el pasado.

Aunque es cierto que la muestra de visitantes que escriben en el libro no puede ser considerada representativa del público total, si atendemos al sondeo estatal existe una amplia aceptación de la apertura limitada de la cueva (el $57 \%$ de la población opina que debería abrirse a un número limitado de personas, siempre y cuando no haya riesgo de deterioro), aunque el $72,1 \%$ cree que son los expertos quienes deben opinar sobre este riesgo y quienes tienen que tomar la decisión final. Existe un rechazo generalizado a que sean los políticos los que decidan (sólo un 1,1\% apoya esta idea).

El día (18 de enero de 2014) en que se anuncia el inicio del plan de visitas experimentales, como parte del Programa Altamira, lo que destaca en los comentarios en las redes y medios digitales es la carga negativa asociada a la noticia (especialmente en el área próxima), que es contemplada como una decisión "política", no técnica, y guiada, supuestamente, por favoritismos y clientelismos. Existe, en el imaginario colectivo, una conexión difusa entre los problemas de conservación del sitio y la gestión política del mismo. Esta opinión también es publicada en los medios de comunicación por parte de algunos miembros del colectivo científico (VICENT; MARTíNEZ; CHAPA, 2014). Retomaremos este aspecto al valorar la dimensión política.

En la dimensión estética (que es difícilmente cuantificable, pero de suma importancia en este caso) se puede considerar que Altamira sigue siendo relevante. Los responsables del estudio Altamira en el arte consideran que tanto el valor de la contemplación, como el de la influencia en los procesos de creación, se han mantenido en los últimos cuarenta años. Para esta afirmación han tenido en cuenta diversas circunstancias.

En primer lugar, el número de referencias de artistas actuales frente a los "históricos", que es similar. El arte rupestre aportaba a los artistas de las vanguardias históricas una nueva realidad plástica hacia la que dirigir la mirada. Y esto sigue siendo así para más de un artista contemporáneo, sobre todo en el aspecto formal (especialmente el uso de los volúmenes, las texturas y el soporte como recurso expresivo), de forma destacada para el expresionismo abstracto (desde Paalen hasta Elaine de Kooning). Otro aspecto es la influencia conceptual, más importante en el pasado, entre 1948 y 1950, a través de la Escuela de Altamira, que jugó un importante papel en la regeneración de la creación artística contemporánea tras la guerra civil, a pesar de que era, a la vez, una plataforma de legitimación del régimen a través de la cultura.

En segundo lugar, las referencias conocidas de arte rupestre en la primera mitad del siglo XX frente al panorama actual, mucho más amplio. Este factor es clave en el proceso de normalización de Altamira: el incremento de 
6. Un ejemplo de utilización de la imagen de Altamira I imagen Manuel Santos. Fondos documentales del $\mathrm{MNCIA}$

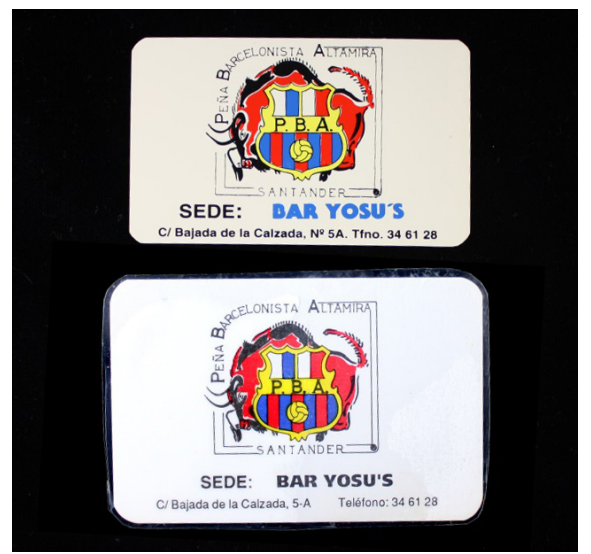

sitios con arte rupestre en todo el mundo. Quizá el mejor ejemplo es el hecho de que Altamira se declarase patrimonio mundial en 1985, y que en 2008 esta declaración se ampliase a todo el arte rupestre paleolítico del norte de España.

Por último, la dificultad/facilidad de acceso a la cueva. Esta circunstancia condiciona enormemente uno de los principales aspectos estéticos del sitio, que es la experiencia de la contemplación. Sin embargo, hay que señalar que un buen número de visitantes (un 36\%) no está nada de acuerdo con la posibilidad de cambiar el ambiente y la atmósfera de la neocueva para emular la cueva original, mientras un $24,7 \%$ estaría bastante de acuerdo o muy de acuerdo con ello. A esto se añade el grado de facilidad de acceso a imágenes que reproducen Altamira. Es obvio que con los avances en las técnicas de reproducción la imagen de Altamira ha ido evolucionando a lo largo del tiempo.

En los objetos analizados en el estudio "Altamira en la cultura material" se constató que la fuente de información suele ser indirecta (reproducciones y recreaciones de las pinturas originales, especialmente los dibujos de Henri Breuil, algo que también es perceptible en el estudio "Altamira en la escuela") y concretamente los bisontes de la Sala de Polícromos (sobre todo los bisontes encogidos). Con el paso del tiempo, la reproducción de estos bisontes se vio favorecida por ser éstas las imágenes más fácilmente reconocibles por el gran público, a pesar de que cada vez es más notable el recurso a imágenes fotográficas en lugar de reproducciones (esto se aprecia bien en los manuales escolares).

Por otro lado, es reseñable el uso de la imagen de Altamira (MONFORTE, 2011: 161-186) para un consumo estético desprovisto del aura del arte, proliferando todo tipo de soportes: suvenires (llaveros, pegatinas, lápices, relojes, etc.), objetos conmemorativos (medallas, sellos) y objetos variados con clara intencionalidad identitaria: equipo de rugby, peña de fútbol (imagen 6), zapaterías o la ADIC (Asociación para la Defensa de los Intereses de Cantabria).

Respecto a la dimensión documental ("Altamira en la producción de conocimiento"), pese a que, desde el descubrimiento de Altamira, han aparecido numerosas evidencias del mismo contexto crono-cultural, podemos afirmar que el sitio ha mantenido su valor gracias a la labor mediadora del museo, a pesar de la imposibilidad práctica de llevar a cabo investigaciones en la cueva (salvo las aplicadas a su conservación). Hay que decir que la importancia de Altamira como yacimiento arqueológico siempre ha estado supeditada a la excepcionalidad de sus pinturas. Existen numerosos yacimientos en la misma cornisa cantábrica con un registro arqueológico más potente que el de Altamira, si bien la conjunción de sacralidad y hallazgos es lo que 
ha llevado a plantear la hipótesis de Altamira como santuario rupestre y lugar de agregación (LASHERAS, 2003).

La visibilidad de Altamira en la literatura científica reciente está marcada por sus problemas de conservación: cuando se habla de Altamira, suele ser para hablar de sus problemas. En las consultas hechas en WoS y PoP/Google Académico se puede percibir un incremento de la presencia de Altamira desde 1999, cuando Saiz-Jiménez y su equipo empiezan a publicar sus trabajos sobre conservación.

La dimensión educativa (el uso de Altamira como recurso educativo) está, a día de hoy, potenciada por la mera existencia de una infraestructura como el museo. La creación del nuevo museo (2001) ha maximizado el potencial didáctico del sitio, independientemente de que la cueva original se pueda visitar o no. En todo caso, esta hipotética visita a la cueva original nunca se podría hacer en las condiciones de observación que proporciona la neocueva, al margen del restante dispositivo museográfico. De ser cierta la intuición de que el discurso docente (rastreable a través de los manuales escolares) lleva un retraso de unos veinte años respecto a los avances científicos (sólo recientemente se empieza a distinguir crono-culturalmente el arte rupestre franco-cantábrico del arte rupestre levantino en estos manuales), es posible que en unos pocos años la temática relacionada con la conservación y fragilidad del arte rupestre de Altamira pase a ocupar un papel principal en los libros de texto, por delante del propio valor artístico o documental.

La dimensión económica era uno de los aspectos cruciales antes de comenzar el proyecto, por razones teóricas, metodológicas y empíricas. Las razones teóricas residen en nuestra propuesta de considerar el valor económico como parte del valor social, y no como una alternativa opuesta o yuxtapuesta a éste, algo bastante frecuente en la literatura relacionada con el valor patrimonial (por ejemplo, MASON, 2002). Las metodológicas radican en la factibilidad de hacer confluir inteligiblemente la ciencia económica con las restantes disciplinas implicadas, lo que creemos que ha sido demostrado.

Las razones empíricas merecen un aparte. Se trataba de obtener información relativa al argumento, reiterado por agentes diversos (sobre todo locales y regionales), de que la situación actual de la cueva tiene repercusiones económicas para el conjunto de la población. Este argumento tiene raíces históricas, ya que Altamira se consolidó como un atractivo turístico en los años 60: entre 1955 y 1973, el número de visitantes anuales a la cueva pasa de 55.000 a 173.000 . Además, esta industria turística no es ajena a la proliferación de las imágenes icónicas de Altamira y a su utilización como marca comercial en numerosos objetos y elementos de la cul- 
tura material. Es ahí cuando adquiere un considerable peso específico en el entorno, lo cual es un elemento a tener en cuenta en el imaginario de la población local a día de hoy, debido a la evolución experimentada desde los años 80 del siglo pasado. Dichos años fueron de agitación y crisis, marcados por la reconversión industrial, que afectó a la minería y la industria de la región, lo que motivó que cualquier recurso económico alternativo (como el turismo) fuese visto como una tabla de salvación. En ese contexto se produce la restricción de las visitas a Altamira, y la profesionalización de su gestión (ya en los años 90), lo que propicia un alejamiento emocional de la población local respecto al sitio y la percepción de una pérdida económica.

Los folletos que circulan hoy por la oficina de turismo de Santillana del Mar muestran Altamira siempre en segundo plano, como un atractivo más de Santillana, mientras las guías oficiales de Cantabria crean una distancia simbólica entre ambas, primando la visita a otras cuevas que sí están gestionadas desde la comunidad. Ello a pesar de que Altamira determinó la decisión de realizar el viaje en un $56 \%$ de los visitantes encuestados, y de la importancia de Altamira en la economía cántabra.

El impacto total generado por los visitantes del museo se estima en 36,2 millones de euros (precios básicos), de los cuales 28 millones serían el impacto directo, y el resto los impactos indirectos. El valor del multiplicador se sitúa, por lo tanto, en 1,29 (las estimaciones realizadas siguiendo esta metodología suelen situar este valor entre 1 y 1,5). Los puestos de trabajo asociados a este impacto se estiman en 558. No existen evidencias de que la apertura de la cueva original amplificase, por sí sola, estos efectos económicos. Salvo una entrada masiva de visitantes en la cueva, no se produciría un efecto relevante sobre las cifras de turistas de la región ni tendría por qué incrementarse el gasto diario medio.

Para finalizar con esta síntesis, abordaremos la dimensión política. Esta dimensión ya es intrincada de por sí, al integrar un componente simbólicoidentitario y un componente asociativo-comunitario, que no siempre son coincidentes, que en sí mismos pueden albergar tendencias dispares, y que muchas veces responden a intereses disímiles e incluso antagónicos. Todo esto se complica en el caso de Altamira.

Uno de los conflictos detectados gira en torno al museo, a cuyos criterios se oponen determinados actores sociales (ciertos políticos y prehistoriadores regionales). Otro se relaciona con la disminución en la influencia de los habitantes de Santillana en la gestión de las visitas, como sucedía en épocas anteriores, donde las redes clientelares incidían directamente en la posibilidad y forma de visitar la cueva. La profesionalización del museo conllevó la ruptura de esas redes clientelares, y la aparición de otros conflictos rela- 
cionados con dinámicas laborales. En consecuencia, la gestión se fue identificando con la intervención de políticos de Madrid y de científicos ajenos a Cantabria, así como con efectos económicos negativos, como la supuesta disminución del beneficio generado por las visitas o la expropiación de los terrenos colindantes a la cueva. Esto contrasta, además, con la percepción de una mercantilización, a través de paquetes turísticos exprés y de la homogeneización de la visita.

A una escala regional, algunos agentes demandan la competencia en la gestión de la cueva, mientras otros aceptan la gestión estatal o proponen fórmulas alternativas de cogestión. La mayoría de visitantes de otras comunidades es ajena a esta cuestión (como se aprecia en la encuesta). La reciente reivindicación regionalista de la identidad cántabra generó una negociación identitaria que no se ha cerrado, que se materializa en la mencionada disputa en torno a la competencia por la tutela y la gestión del sitio. Esta reivindicación, singular en una antigua provincia de Castilla (desde hacía siglo y medio), choca así con la condición de símbolo identitario español, que hunde sus raíces en la propia historia de Altamira. Porque el destino de Altamira estuvo muy condicionado por el hecho de hallarse en territorio de España, y adquirió desde el principio un valor simbólico del que nunca ha acabado de desprenderse (MORO, 2009).

Hace cien años, España trataba de consolidarse como identidad nacional, en un territorio prácticamente desarticulado, muy desequilibrado, sin buenas infraestructuras viarias, sin medios de comunicación y con porcentajes de analfabetismo muy altos (del 64\% en 1900: LIÉBANA, 2009). A principios del siglo XX, "España", como concepto, sólo existía para las élites y las clases urbanas. La generalización de la escolarización (en 1900 un 60\% de la población en edad escolar estaba sin escolarizar), aunque deficiente, fue un instrumento esencial en la difusión de símbolos "nacionales", como Altamira. El mismo Alfonso XIII empieza a visitar anualmente la cueva sólo en los años 20.

Tampoco será hasta 1924 cuando se inician los trabajos para "adecuar" los accesos y el interior de la cueva a la visita. Las palabras dirigidas por el padre Carballo a Alfonso XIII en ese momento son elocuentes: "la Gruta de Altamira, que debiera ser gloria de España ante extranjeros, resulta lo contrario; es para nosotros denigrante tenerla en semejante abandono" (CARBALLO, 1950). El duque de Alba es quien asume la responsabilidad de la cueva. En 1925 se firma la Escritura de cesión de la Explotación, Conservación y Nuevas Investigaciones de la Cueva de Altamira entre el Ayuntamiento y el duque de Alba, por la cual el Ayuntamiento cede la gestión, pero no la propiedad, de la cueva, por no más de 99 años y con base en el convenio. La asunción de la gestión queda, por lo tanto, en manos de la oligarquía gobernante y residente en Madrid. 


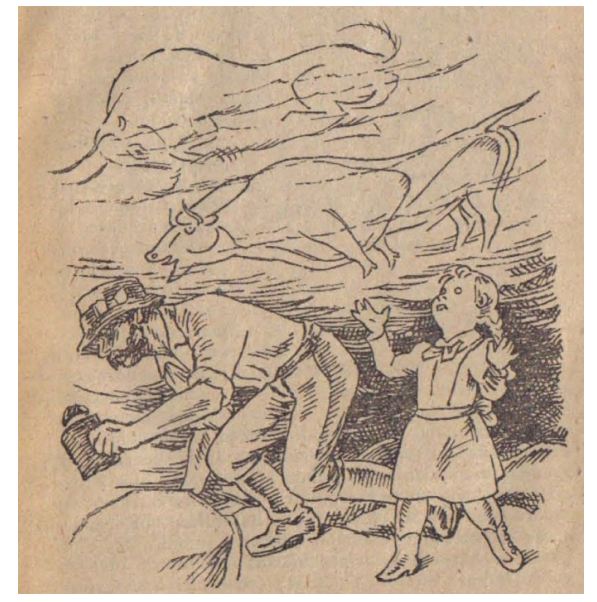

7. Una recreación de Joan Junceda | fuente MUNTADA BACH, J. (1942) Santa tierra de España. Barcelona: Imprenta-editorial Altés, 1942. Imagen Fondo documental MANES. UNED, Biblioteca central
Tras el paréntesis republicano (la cueva se salvó in extremis de ser bombardeada por la Legión Cóndor), su valor político-simbólico adquiere una nueva dimensión durante la época franquista. Mediante la progresiva implantación de los medios de comunicación de masas y de una escolarización generalizada, pero profundamente pautada por las directrices ideológicas del régimen, Altamira deviene en un símbolo nacional popularizado.

Generaciones de españoles son educadas en historia a partir de la lista de los reyes godos, el sol que nunca se pone y la imagen de los bisontes de Altamira (imagen 7). Además, en 1940 se crea el Patronato de la cueva de Altamira (en 1944 se amplía a todas las cuevas de Santander), como parte de la estrategia de creación del "Nuevo Estado", que dependerá de la Dirección General de Bellas Artes: el centro de decisiones se escora decididamente hacia la capital del Estado (en 1944 la alcaldía de Santillana queda excluida del Patronato; en 1969 el Ayuntamiento interpondrá una demanda judicial). Mientras, el modelo de gestión de la cueva se mantiene y afianza con base en relaciones clientelares en las que juegan un papel fundamental determinados agentes locales, siempre bajo las directrices del Patronato, asesorado por los técnicos.

En 1978, cuando ya han saltado las alarmas por el estado de conservación de la cueva (cerrada en 1977), el Ayuntamiento cede el pleno dominio al Ministerio de Cultura (al mismo tiempo que se inicia la creación del nuevo modelo autonómico del Estado), quien crea, en 1979, el Museo y Centro de Investigación de Altamira (MNCIA) y el Patronato de éste. Un poco antes, en 1976, se crea la Asociación para la Defensa de los Intereses de Cantabria (ADIC), que dará lugar a la formación del Partido Regionalista Cántabro. Es un núcleo activo que reclama la competencia sobre Altamira, y se opone al cierre provisional de la cueva. Nadie reparó entonces en el conflicto de "lógicas" que suponía la yuxtaposición de la promoción del regionalismo y la cesión de la cueva al Ministerio.

En 1985 se firma un convenio entre administraciones (incluida la autonómica) donde se modifica la composición del Patronato (el/la presidente/a de Cantabria asume la presidencia) y donde el museo se convierte en Museo Nacional y Centro de Investigaciones de Altamira (conforme a la reciente Ley de Patrimonio Histórico Español).

Este año, en el que, además, Altamira es declarada patrimonio mundial, podría haber sido el inicio de una modernización modélica en la gestión de Altamira, pero se mantuvieron las prácticas de gestión pre-existentes, se renovó tarde (1992) el equipo de dirección, y se tomaron medidas preventivas de forma poco sistemática. Tampoco hubo continuidad en los equipos que se responsabilizaron del seguimiento del estado de la cueva, primero dependientes de la Universidad de Cantabria (años 80), luego del CSIC 
(década de 2000). Estos últimos recomendaron (SAIZ-JIMÉNEZ; CUEZVA; JURADO et ál., 2011: 42) mantener la cueva cerrada al público para evitar el deterioro de las pinturas.

El inicio de un plan de visitas experimentales, en 2012, en el marco del Programa Altamira, dio lugar a una nueva versión de la polémica entre expertos partidarios del cierre por precaución y expertos partidarios de su apertura controlada, con elementos políticos de fondo.

\section{CONCLUSIONES}

Como cualquier entidad en el mundo, la Altamira actual es un producto de su propia historia, tiene una biografía, marcada por unas condiciones sociales (políticas, económicas, culturales) de emergencia, constitución y uso. Utilizar el término "biografía" para referirnos a un objeto, sitio o lugar concreto no es una elección gratuita, ni mucho menos una innovación (desde Appadurai, 1986, hasta la actualidad es un concepto recurrente en la literatura en ciencias sociales).

En torno a Altamira se desarrollan procesos sociales que se articulan a partir del reconocimiento de su existencia; esto es, de su identidad social. Parafraseando a Castilla del Pino: ser es ser algo o alguien, y ser algo o alguien es ser algo o alguien para alguien. Igual que un ser humano es un organismo o cuerpo, y sólo es persona cuando puede interactuar, un objeto o un lugar dejan de ser parte indeterminada del mundo (una pre-existencia) cuando se les otorga una identidad social.

Desde esa condición existencial, el lugar u objeto actúa como un espacio de cambio y negociación de significados, pero generando efectos sociales, que no se restringen a lo simbólico. Esto es lo que permite recurrir a la dialéctica como método de modelización de la realidad patrimonial, y, en última instancia, lo que permitiría incluso hablar de "historia de vida" (donde es el sujeto el que habla, siendo Altamira quien nos cuenta su propia historia a través de las voces y materialidades que le dan sentido e identidad) al tiempo que de "biografía" (que denota un sujeto -el investigador- que nos habla sobre un objeto -Altamira- a partir de sus fuentes de conocimiento).

En todo caso, ni siquiera habría que estar de acuerdo con lo anterior para aceptar que Altamira tiene algún tipo de vida, pues los especialistas saben que la cueva respira, transpira, suda, filtra... y lo hace de un modo (difícil de prever y objetivar) que no se puede reducir a la linealidad de un proceso natural simple. Altamira es un sistema no lineal, en el que confluyen procesos naturales y sociales tanto como valoraciones, por parte de diferentes actores, sobre esos mismos procesos y sus efectos. 
Todos estos actores tienen algo que decir. La participación de la población local no sólo en el conocimiento, sino en la gestión de cualquier bien patrimonial es clave para la socialización del mismo. Y para que esta participación no genere efectos perversos, es preciso que se asiente sobre el fomento del aprecio al sitio. Cualquier estrategia de conservación preventiva que se adopte en el futuro, sobre todo si aspira a superar o minimizar los conflictos detectados, y a mantener Altamira como un referente cultural, tiene que partir de este principio.

\section{Equipo de trabajo}

Coordinadores: Felipe Criado-Boado y David Barreiro (arqueólogos, Instituto de Ciencias del Patrimonio, Incipit).

Equipo de dirección: Cristina Sánchez-Carretero (antropóloga, Incipit); Virtudes Téllez Delgado (antropóloga); Eva Parga-Dans (socióloga).

Investigadores: Fidel Martínez y Xesús Pereira (economistas, U. Santiago de Compostela), Xurxo Ayán (arqueólogo, U. País Vasco), Manuel Santos-Estévez (arqueólogo), Pilar Fatás y José Antonio Lasheras (Museo Nacional y Centro de Investigaciones de Altamira), Alicia Herrero (historiadora, Museos Estatales), Gonzalo Ruiz-Zapatero (arqueólogo, U. Complutense), Estíbaliz García (historiadora), Manuel Gago, Xosé Pereira y Sabela Cereijo (comunicólogos, U. Santiago de Compostela).

Asesoría: Antoni Nicolau y Teresa Marot (Kultura), personal del Laboratorio Permanente de Público de Museos, del Ministerio de Educación, Cultura y Deporte.

Agradecimientos: por su colaboración al personal de EDESGA, del Incipit y del Museo Nacional Centro de Investigación de Altamira.

Reconocimientos: a la aportación de todas aquellas personas que han respondido a preguntas o, simplemente, se ha ofrecido para la investigación. Ellas, junto con muchas más, dan sentido y vida a la Cueva de Altamira. 


\section{BIBLIOGRAFÍA}

- AppadurAl, A. (Ed.) (1986) La vida social de las cosas. Perspectiva cultural de las mercancías. Barcelona: Grijalbo, 1986

- BARREIRO, D. (2012) Arqueología aplicada y patrimonio: memoria y utopía. Complutum, 2012, vol. 23 (2), pp. 33-50

- CARBAllo, J. (1950) Marcelino S. de Sautuola. Santander: Imp. de la Librería Moderna, 1950 (Antología de escritores y Artistas Montañeses; 14)

- CRIADO, F. (1996) Hacia un modelo integrado de investigación y gestión del Patrimonio Histórico: La cadena interpretativa como propuesta. $\mathrm{PH}$ boletín del Instituto Andaluz del Patrimonio Histórico, 16, septiembre, 1996, pp. $73-78$

- GONZÁLEZ, M. (1999) Investigación y puesta en valor del Patrimonio Histórico. Planteamientos y Propuestas desde la Arqueología del Paisaje. Humanidades y Ciencias Sociales 1999. Tesis doctorales en cdrom. Universidade de Santiago de Compostela, 1999

- GONZÁLEZ-PÉREZ, C; PARCERO-OUBIÑA, C. (2011) A Conceptual Model for Cultural Heritage. Definition and Motivation. Revive the Past: Proceedings of the 39th Conference in Computer Applications and Quantitative Methods in Archaeology. Beijing, China, 12-16 de abril de 2011

- LASHERAS, J. A. (ed.) (2003) Redescubrir Altamira. Madrid: Turner, 2003

- LIÉBANA, A. (2009) La educación en España en el primer tercio del siglo XX: la situación del analfabetismo y la escolarización. Madrid: Universidad de Mayores de Experiencia Recíproca, 2009

- MASON, R. (2002) Assessing Values in Conservation Planning: Methodological Issues and Choice. En TORRE, M. DE LA (ed.) Assessing the Values of Cultural Heritage. Research Report. Los Angeles: The Getty Conservation Institute, 2002, pp. 5-30

- MONFORTE, P. F. (2011). Altamira, símbolo, identidad y marca. En Actas del Simposio Internacional El patrimonio cultural como símbolo. Valladolid: Fundación del Patrimonio Histórico de Castilla y León, 2011, pp. 161-186
- MORO, Ó. (2009) Art caves as symbolic spaces: the case of Altamira. En MARÍKOVÁ-KUBKOVÁ, J; SCHLANGER, N.; LEVIN, S. (dir.) Sites of Memory between scientific research and collective representations. Praga: Archaeologicky ústav Akademie ved Ceske Republiky, 2009

- SAIZ-JIMÉNEZ, C.; CUEZVA, S; JURADO, V. et ál. (2011) Paleolithic Art in Peril: Policy and Science Collide at Altamira Cave. Science, 334, 2011

- VICENT, J.; MARTÍNEZ, M.+ I.; CHAPA, T. (2014) Altamira: ¿ciencia o 'marketing'? EL PAÍS, Sección Cartas al Director (09/03/2014) [en línea] <http://elpais.com/ elpais/2014/03/08/opinion/1394295769 969712.html> [Consulta: 5/2/2015] (versión impresa: p. 46) 